\title{
PRECISAMOS FALAR DE GÊNERO: POR UMA EDUCAÇÃO DEMOCRÁTICA
}

\author{
TENEMOS QUE HABLAR DEL GÉNERO: PARA UNA EDUCACIÓN \\ DEMOCRÁTICA
}

WE MUST TALK ABOUT GENDER: FOR A DEMOCRATIC EDUCATION

\author{
Sandra Maciel de ALMEIDA ${ }^{1}$ \\ Lisete $\mathrm{JAEHN}^{2}$ \\ Mônica VASCONCELLOS ${ }^{3}$
}

RESUMO: Os discursos moralizantes tem sido a tônica de uma agenda conservadora, no Brasil contemporâneo, como forma de abrir caminho para o conservadorismo político devassar as possibilidades de avanço social e democrático, construídas nos últimos quinze anos. Este cenário causa perplexidade e é grave para qualquer democracia. Profissionais que atuam na educação têm sido acusados de promover a chamada ideologia de gênero e as políticas têm excluído temas referentes às questões de gênero do currículo escolar, contrariando recomendações dos documentos oficiais, como o Plano Nacional de Educação, as Diretrizes Curriculares e os Parâmetros Curriculares Nacionais. Na contramão deste entendimento, grupos formados por representantes de diferentes setores sociais, e em especial, professores/as, estudantes da escola básica e universidades têm agido e reagido para problematizar esta concepção e assegurar o respeito e a valorização da diversidade, em seu sentido mais amplo, reforçando a ideia da escola como espaço legítimo de formação das novas gerações, por meio da adoção de práticas democráticas. Defendemos que as questões sobre gênero e sexualidade já permeiam o cotidiano de estudantes da escola formal, o que é confirmado pelas duas iniciativas desenvolvidas em 2017, que apresentamos: o Grupo PET Conexões de Saberes/Interdisciplinar e o I Colóquio sobre Gênero e Educação. Em tempos de ataque à democracia é urgente a defesa de uma escolarização democrática e igualitária, assumindo-se a natureza plural do espaço da escola e das universidades públicas.

PALAVRAS-CHAVE: Educação democrática. Gênero. Conservadorismo. Resistência.

\footnotetext{
${ }^{1}$ Universidade Federal Fluminense (UFF), Niterói - RJ - Brasil. Docente na Faculdade de Educação. Coordenadora do Núcleo de Etnografia, Educação e Justiça Social. Membro do Formar - Grupo de Pesquisa em Formação e Práticas Pedagógicas e do Núcleo de Didática e Formação de Professores. ORCID: <https://orcid.org/0000-0001-5201-0735>. E-mail: sandramacieldealmeida@gmail.com

${ }^{2}$ Universidade Federal Fluminense (UFF), Niterói - RJ - Brasil. Docente na Faculdade de Educação. Membro e Vice-Coordenadora do Formar - Grupo de Pesquisa em Formação e Práticas Pedagógicas e do Núcleo de Didática e Formação de Professores. Membro do CDC - Grupo de Pesquisas Currículo, Docência e Currículo. ORCID: <https://orcid.org/0000-0002-1208-4577>. E-mail: lisetej@ gmail.com

3 Universidade Federal Fluminense (UFF), Niterói - RJ - Brasil. Docente na Faculdade de Educação/Programa de Pós-Graduação em Educação. Coordenadora do Formar - Grupo de Pesquisa em Formação e Práticas Pedagógicas e do Núcleo de Didática e Formação de Professores. Tutora do Grupo PET/Conexões de Saberes. ORCID: <https://orcid.org/0000-0003-2938-2121>. Email: monicavasconcellos@id.uff.br
} 
RESUMEN: Los discursos moralizantes ha sido la tónica de una agenda conservadora en el Brasil contemporáneo como una forma de allanar el camino para el conservadurismo político, revela las posibilidades de progreso social y democrático, construido en los últimos 15 años. Esta situación provoca desconcierto y es grave para cualquier democracia. Profesionales de la educación han sido acusados de promover la llamada ideología de género`y las políticas tienen eliminado temas en cuestiones de género en el currículo escolar, contrariamente a las recomendaciones de los documentos oficiales, tales como el plan nacional de Educación, plan de estudios directrices y los parámetros curriculares nacionales. Contra el grano de este entendimiento, grupos compuesto por representantes de diferentes sectores sociales y en particulares, tutores, estudiantes de la escuela primaria y las universidades tienen actuó y reaccionó a problematizar este diseño y garantizar el cumplimiento y la reconocimiento de la diversidad en su sentido más amplio, reforzando la idea de la escuela como un espacio legítimo para la formación de nuevas generaciones, mediante la adopción de prácticas democráticas. Sostenemos que las preguntas sobre el género y la sexualidad ya están presentes en la vida cotidiana de los estudiantes en la escuela formal, que es confirmado por las iniciativas desarrolladas en el año 2017, presentamos: PET Grupo de conexiones/interdisciplinario y el I Simposio sobre género y educación. En tiempos de ataque a la democracia es una necesidad urgente de defender una educación democrática e igualitaria, asumiendo la naturaleza plural del espacio de la escuela y las universidades públicas.

PALABRAS CLAVE: Educación democrática. Género. Conservadurismo. Resistencia.

ABSTRACT: Moralizing speeches have been used by a conservative agenda, in contemporary Brazil, as a form of opening doors for political conservatism to stop any possibility for the social and democratic advances that were built in the past fifteen years. Such a scenario causes perplexity and is considered seriously problematic for democracy. Education professionals have been accused of promoting the so called 'gender ideology', while politics have been excluding topics concerning gender from their syllabus, contradicting recommendations from official documents as Plano Nacional de Educação, Diretrizes Curriculares and Parâmetros Curriculares Nacionais. On the other hand, groups formed with representatives coming from different social sectors, and-especially - teachers, basic education students and universities, have been acting and reacting in order to question such conceptions and secure the respect and valuing of diversity, in its widest meaning, reinforcing the idea of school as a place for a legit construction of new generations through the use of democratic practices. We defend that topics on gender and sexuality are already part of students' routine in formal school, what is confirmed based on two initiatives developed in 2017, that we present: Grupo PET Conexões de Saberes/Interdisciplinar and the I Colóquio sobre Gênero e Educação. In times of striking against democracy, it is urgent to defend an equal and democratic schooling, assuming the diverse nature in schools and public universities.

KEYWORDS: Democratic education. Gender. Conservatism. Resistence.

\section{Introdução}

RIAEE - Revista Ibero-Americana de Estudos em Educação, Araraquara, v. 13. n. esp. 2, p. 1503-1517, set., 2018. ISSN: 1982-5587. 
A retórica conservadora tem buscado espalhar o medo e a insegurança através de discursos moralizantes, como forma de abrir caminho para o conservadorismo político devassar as possibilidades de avanço social e democrático, construídas nos últimos quinze anos, no Brasil. Dentre estes discursos estão formas equivocadas de se referir à concepção sobre gênero, na medida em que elas estariam ameaçando a organização das famílias, no sentido tradicional, e que estaríamos reféns de uma tal 'ideologia de gênero', promovida pela escolarização, de modo geral, que estaria destruindo os valores desta família através do processo pedagógico.

Como educadoras, entendemos que este cenário causa perplexidade e é grave para qualquer democracia. Por isso mesmo, merece uma análise mais criteriosa para ser compreendido e, ao mesmo tempo, ações que lhe sirvam como resistência e enfrentamento. O propósito deste artigo é dar sentido a estas duas possibilidades, apresentando alguns resultados desta tessitura numa universidade pública brasileira.

Através da problematização da discussão sobre gênero, discutimos os reflexos do pensamento político conservador nos espaços educativos, pela tentativa de retirar as discussões sobre gênero da legislação educacional, tanto em âmbito nacional, quanto estadual e municipal. $\mathrm{O}$ artigo defende e apresenta resultados da criação de territórios de diálogo que permitem o enfrentamento destas questões que atingem a democracia e os direitos individuais e coletivos da sociedade brasileira. Assume-se, assim, a natureza plural da universidade pública como espaço da diversidade e do diálogo.

\section{Por que discutir gênero se tornou uma ameaça?}

Esta questão tem nos intrigado por inúmeras vezes, já que a história da luta das mulheres contra a opressão está registrada em muitos momentos da história da civilização, e o feminismo, como um movimento social organizado, é reconhecido, no Ocidente, desde o século XIX. Até mesmo os estudos de gênero, que 'inventaram' o termo, são datados do final da década de 1960, nos Estados Unidos e assumem-se como um campo de pesquisas acadêmicas, chegando ao Brasil na década de 1990 (LOURO,1997).

Somente quando olhamos para a organização social e política do nosso país, é que começamos a compreender a ameaça que o fato de falar sobre gênero produz, especialmente quando isto acontece no contexto escolar. O Brasil herdou e ainda não superou um modelo patriarcal e oligárquico de organização social, no qual o poder 
simbólico e cultural está conectado ao poder econômico, o que resulta em - e justifica um poder político conservador.

Começamos, portanto, explorando a concepção de conservadorismo, buscando fazer um recorte, pois ela é bastante ampla e complexa, tal como fizeram Sepulveda, J. A.; Sepulveda, D., (2016). A primeira conclusão a que os autores chegam é que não há uma teoria política comum para definir os conservadores, fazendo com que a esta palavra sejam atribuídos muitos sentidos no cotidiano da vida social, relacionando-se o termo, inclusive, ao comportamento humano, o que o torna, muitas vezes, ambíguo. "Assim, uma pessoa pode ser politicamente inovadora e ter condutas conservadoras com relação à família ou até mesmo em relação a práticas sexuais" (SEPULVEDA J. A.; SEPULVEDA D., 2016, p. 142). De todo modo, admite-se haver "[...] uma retórica do conservadorismo político, a qual se apresenta como enfrentamento a qualquer mudança de ordem política que se proponha, de alguma forma, a modificar as relações de poder estabelecidas em uma sociedade" (SEPULVEDA J. A.; SEPULVEDA D., 2016, p. 143).

Os autores identificam Edmund Burke como quem inaugurou o conservadorismo político ao criticar a Revolução Francesa, sendo que a sua questão central foi, justamente, o combate às modificações nas relações sociais e à ascensão de novas classes sociais ao poder. Portanto, o discurso político conservador se efetiva sempre que suas teses “[...] são empregadas para evitar qualquer transformação na ordem social ou melhorias reais para as classes trabalhadoras, ou para qualquer grupo minoritário" (SEPULVEDA J. A.; SEPULVEDA D., 2016, p. 144).

Concordando com Sousa Santos (2018), entendemos que tal contexto representa uma grave ameaça à democracia brasileira e faz parte de uma estratégia que o pensamento político conservador tem usado, buscando destruir as conquistas sociais e democráticas alcançadas nos últimos quinze anos. Diante deste quadro, o autor identifica a realidade brasileira atual como perplexa e paralisante, apontando quatro razões principais: 1) a conjuntura eleitoral atual após o golpe institucional de 2016; 2) a invisibilidade ou ausência, no contexto atual, de uma grande parcela da população excluída cultural e economicamente falando (população pobre, negra, indígena, jovem, moradores das favelas, dos presídios); 3) a intervenção imperial americana que se efetiva no país desde o século XX. Ela possibilitou a ditadura militar de 1964 e hoje continua a acontecer por uma intervenção na opinião pública e nos protestos sociais através das instituições financiadas 
pelos EUA, de acordo com os interesses políticos e econômicos americanos ${ }^{4}$. A intervenção também acontece no processo político, pelo financiamento de partidos através de empresas multinacionais e às vezes, por igrejas. Também acontece no sistema judicial, de forma indireta e sutil, visando promulgar a defesa do princípio da liberdade em detrimento da igualdade, tendo como eixo central a defesa absoluta da propriedade privada, argumentando-se que esta é “[...] a única ideologia judiciária legítima porque é a única não política" (SOUSA SANTOS, 2018, p. 5); 4); as dificuldades das forças democráticas encontrarem caminhos de resistência e de alternativa eficaz e com credibilidade porque há este domínio, descrito acima.

Acrescentamos às argumentações de Boaventura Sousa Santos uma quinta razão pela qual o momento atual brasileiro é perplexo e paralisante: a intervenção militar no estado do Rio de Janeiro, no ano de 2018, sendo uma demonstração clara da disposição do pensamento político conservador de usar qualquer meio, inclusive a força física, militar, para se alcançar determinados fins.

Logo, o que se espera, neste modelo de organização, é a conservação das estruturas, através de uma estabilidade nas práticas culturais, sociais e materiais, promulgando-se valores tradicionais. Ou seja, não cabe questionar o papel dos sujeitos, nem mesmo as estruturas que garantem tal organização, como a política, a classe social, a família, a religião e a escola. Também não cabe questionar o papel do masculino, do feminino ou a sexualidade porque estes não são reconhecidos como sendo uma construção social. Igualmente não cabe discutir a inclusão das minorias porque, afinal, segundo uma visão liberal durkheiminiana, elas já ocupam o seu devido espaço na sociedade, cabendo ao Estado apenas prover as condições mínimas de sua sobrevivência, por mais que estejam marginalizadas. Tais concepções estão naturalizadas e porque não dizer, cristalizadas no pensamento político conservador e, portanto, são imutáveis do seu ponto de vista.

Portanto, se não faz sentido discutir mudanças estruturais, não devemos falar sobre gênero, especialmente porque discutir a sexualidade, neste contexto, fará esvair entre os dedos as certezas sagradas em torno do sexo que consolidamos ao longo dos séculos, graças aos preceitos de uma fé cega e dogmática, sustentada pelo pensamento conservador e tradicional. Esta é, ainda, nos tempos hodiernos, a base que justifica, do ponto de vista político e filosófico, a negação da temática de gênero, no Brasil patriarcal e oligárquico,

${ }^{4}$ Para maiores esclarecimentos de como a intervenção americana acontece na opinião pública e nas manifestações sociais, no Brasil, ver Sousa Santos (2018, p. 4). 
especialmente a partir da perspectiva política.

\section{Os reflexos do pensamento político conservador na educação}

A tese da ameaça relacionada ao comportamento, sinalizada por Hirschman apud Sepulveda, J. A.; Sepulveda, D., (2016, p. 147), funciona para amedrontar as pessoas, de modo geral, inclusive os professores, especialmente quando se trata de gênero. A materialização desta ameaça ocorre quando o pensamento conservador busca convencer a sociedade de que há uma "ideologia de gênero", colocando os estudos de um campo de pesquisas como ideológicos e que eles estariam destruindo os avanços recentes da organização familiar tradicional. Afirma-se que "[...] a escola deve se defender de tal ameaça.” (SEPULVEDA J. A.; SEPULVEDA D., 2016, p. 147). Portanto, para não correr este risco, segundo esta visão, a melhor forma de defesa é não falar no assunto, proibindose, legalmente, o termo gênero.

Atribui-se a origem de tal 'ideologia de gênero' a vários contextos, como o marxismo, os estudos de gênero, mas também a iniciativas de instituições, inclusive a organismos internacionais, como a Organização das Nações Unidas (ONU), sendo esta acusada de criar esta ideologia na IV Conferência Mundial sobre a Mulher, realizada em Pequim, no ano de 1995. Tais acusações, além de serem falsas, demonstram o nível de ignorância sobre o conceito. Ao analisarmos os documentos e referenciais referidos, não encontramos 'ideologia de gênero’ em nenhum deles. Encontramos, sim, o reconhecimento de que o papel de masculino e feminino é uma construção social, não sendo determinado como defendem os representantes do pensamento conservador -, e que esta discussão é necessária para a modificação nas relações de poder entre os diferentes gêneros, visando à igualdade. De fato, esta relativização é o ponto que incomoda e é insuportável para o pensamento político conservador porque rompe com a lógica de organização social de modo radical, ou seja, modifica uma estrutura central para o atual modelo social, que é a família tradicional, além de produzir reflexos em todas as demais instâncias da sociedade.

Na Declaração e Plataforma de Ação da IV Conferência Mundial sobre a Mulher (ONU, 1995), além de não encontrarmos nenhuma menção à tal 'ideologia de gênero', há um grande enfoque na igualdade das relações. O conceito de gênero, a noção de empoderamento e o enfoque da transversalidade são considerados as três grandes inovações para a transformação na luta pelos direitos das mulheres. Foi a partir desta

RIAEE - Revista Ibero-Americana de Estudos em Educação, Araraquara, v. 13. n. esp. 2, p. 1503-1517, set., 2018. ISSN: 1982-5587. 
conferência que a instituição passou a usar o termo gênero (ONU, 1995, p. 3).

$\mathrm{Na}$ escola brasileira, esse pensamento está se materializando, incitando-se o "[...] ódio aos professores" (PENNA, 2015, p. 295). Profissionais da educação têm sido acusados, especialmente pelo movimento que se autodenomina Escola sem Partido (SALLES, 2017), de estarem promovendo a "ideologia de gênero" (REIS; EGGERT, 2017). Como afirma Penna (2015, p. 296), “[...] a principal acusação é de que os professores doutrinariam ideologicamente os seus alunos, impondo os seus valores éticos, políticos e sexuais. Sem dúvida, dois elementos estão em foco: a questão de gênero e a questão político-partidária”. Neste sentido, propõe-se a exclusão das temáticas de gênero e de diversidade sexual em documentos como o Plano Nacional de Educação (REIS; EGGERT, 2017) e a Base Nacional Comum Curricular (MACEDO, 2017, p. 517), além da perseguição deliberada a professores, acusados de "doutrinação ideológica de esquerda" (PENNA, 2015, p.264).

As pressões por mudanças e alterações resultaram em projetos de lei como os que tramitam na Câmara e no Senado Federal, desde 2015 e 2016, que propõem alterações na Lei de Diretrizes e Bases da Educação Nacional (LDB) para incorporar as determinações do Programa Escola Sem Partido (MACEDO, 2017, p. 508). A autora informa que "[...] os vínculos dos projetos com o movimento são explicitados nos próprios projetos de lei e a aposta numa relação antagônica entre professores e alunos e pais segue sendo a tônica dos documentos".

No caso específico dos planos de educação, tanto a nível nacional, quanto estadual e municipal, as pressões de setores conservadores para a retirada das referências à palavra gênero dos planos, surtiu efeito. Segundo Reis e Eggert (2017, p. 18), “[...] em relação aos 22 dos 27 Planos Estaduais de Educação aprovados e sancionados na forma de lei, 9 não fazem qualquer referência a palavra gênero e 15 não explicitam o termo gênero nos Princípios ou Diretrizes do Plano ao citar o enfrentamento a toda a forma de discriminação". Neste mesmo rumo seguiu a Base Nacional Comum Curricular - BNCC -, aprovada em dezembro de 2017 , onde houve a retirada do termo do currículo nacional. Embora a retirada das referências à palavra gênero dos planos de educação não impeça os professores de abordar essa temática na escola, pode reforçar estereótipos e servir para legitimar a omissão desse debate nos espaços escolares (GARCIA; MENDONÇA; LEITE, 2015).

Por outro lado, para além da discussão política em torno do termo, as questões 
sobre gênero e sexualidade já estão presentes no cotidiano das escolas, de forma explícita ou implícita, sendo recorrentes, por exemplo, situações de violência contra as meninas e os homossexuais (MACEDO, 2017; REIS; EGGERT, 2017). Baseados em dados de pesquisa realizada junto a integrantes da Parada Gay de Sorocaba-SP, Garcia e Mendonça (2015, p. 57), afirmam que

[...] o preconceito e a homofobia estão presentes com maior força nas relações de proximidade, ou seja, família, grupos religiosos e escola. [Os resultados da pesquisa] Ressaltam, entretanto, a importância da escola em se transformar de ambiente promotor e produtor de homofobia em locus privilegiado de promoção do respeito às diferenças, diversidades e direitos humanos.

Aqui, a universidade também é compreendida como uma possibilidade real de resistência frente às acusações que a comunidade educacional vem sofrendo, no que diz respeito ao debate sobre gênero. Longe de ser um espaço consensual, no qual as divergências a respeito desta temática tenham sido superadas, as instituições universitárias constituem-se em um poderoso espaço de análise e produção de conhecimento. De modo mais específico, entendemos que os cursos de licenciatura, por sua natureza e finalidade, podem ajudar a ampliar e fortalecer esta discussão por meio de propostas que contribuam para a reflexão, a revisão conceitual e a mudança de atitude frente às formas de discriminação ainda presentes em nossa sociedade. Afinal, os licenciandos serão os futuros docentes e gestores das escolas e/ou membros de outras instituições educacionais. No entanto, esta discussão tem sido alvo de disputas entre grupos que provocam questões como: Qual é o lugar do professor no interior das escolas? Existem limites para sua atuação? Em caso afirmativo, quem os define?

Defensores de movimentos conservadores, tal como o Escola Sem Partido, afirmam que estes limites existem e justificam seu ponto de vista assegurando que o trabalho docente não deve, em hipótese alguma, abordar questões que ultrapassem os limites dos conteúdos específicos de cada componente curricular. Argumentam que a escola deve pautar sua atuação por princípios de "[...] neutralidade política, ideológica e religiosa, [com o intuito de evitar] doutrinações" (BRASIL, 2015, p. 2). No entanto, documentos oficiais como as Diretrizes Curriculares Nacionais da Educação Básica ressaltam que a escola tem, sim, a responsabilidade de instigar o desenvolvimento do "[...] ser humano como cidadão pleno, de tal modo que este se torne apto para viver e conviver em determinado ambiente, em sua dimensão planetária" (BRASIL, 2013, p. 10). Para isso precisa 
[...] fomentar processos que contribuam para a construção da cidadania, do conhecimento dos direitos fundamentais, do respeito à pluralidade e à diversidade de nacionalidade, etnia, gênero, classe social, cultura, crença religiosa, orientação sexual e opção política, ou qualquer outra diferença, combatendo e eliminando toda forma de discriminação (BRASIL, 2013, p. 165).

O debate sobre este assunto tem sido acirrado e estudiosos têm se manifestado favoráveis a entendimentos semelhantes a este que destacamos no excerto anterior. Penna (2016, s/p), por exemplo, não só compactua com esta compreensão como adverte que a relevância desta questão pode ser explicada pela necessidade de “[...] desnaturalizar as relações entre os gêneros, questionar a violência contra as mulheres e combater a homofobia". Para ilustrar a relevância desse tipo de abordagem na escola, o pesquisador retoma o tema da redação do Exame Nacional do Ensino Médio (ENEM), proposto em 2015 - "A persistência da violência contra a mulher na sociedade brasileira" - e pondera que em razão desta iniciativa, em apenas um dia, o estado do Espírito Santo teve um aumento no número de ligações anônimas destinadas ao relato de situações de violência cometidas contra as mulheres, traduzidas em mais de 300 denúncias.

Alinhadas a estes esclarecimentos (PENNA, 2016; BRASIL 2013), Vasconcellos e Moreira (2017) acrescentam que a efetivação de um trabalho como este demanda a composição de bases conceituais sólidas, calcadas na perspectiva da educação democrática como meio e fim do processo de escolarização. Argumentam que ao professor cabe, sim, promover discussões que problematizem e valorizem a pluralidade dos grupos excluídos, fundados em valores éticos, de liberdade, justiça e inclusão social.

\section{Possibilidades de resistência via formação de professores: a universidade pública como espaço plural}

Diante do contexto delineado, professores e estudantes de instituições brasileiras têm se dedicado a propor diversas ações na tentativa de lidar, problematizar, enfrentar ou mesmo sobreviver às pressões que se impõem às escolas e às universidades, buscando-se fomentar encaminhamentos voltados para a valorização da educação democrática, como projeto de formação de nossa sociedade. No caso da Faculdade de Educação da Universidade Federal Fluminense, não tem sido diferente. Dentre as ações empreendidas até o momento, destacamos duas iniciativas realizadas por docentes de Didática, desta instituição, que trataram, diretamente, da temática em questão: as atividades realizadas 
pelo Grupo PET Conexões de Saberes/Interdisciplinar ${ }^{5}$ e o I Colóquio sobre Gênero e Educação ${ }^{6}$.

De modo geral, as ações do Grupo PET Conexões de Saberes/Interdisciplinar estão organizadas em um ciclo que compreende: estudo da literatura da área da Educação; imersão nas escolas selecionadas e ampliação destes estudos a partir das questões que lá emergem; planejamento e desenvolvimento de atividades pontuais junto aos alunos da escola envolvida; definição coletiva dos temas de interesse desses alunos, para que sejam contemplados pelos projetos interdisciplinares a serem desenvolvidos; definição, em conjunto com os professores da escola, a propósito dos conteúdos curriculares que serão abordados; produção de materiais didáticos e implantação dos projetos, nas referidas escolas (VASCONCELLOS; SANTIAGO, 2017).

Um dos objetivos do grupo trata de provocar o fortalecimento da política de diversidade nas instituições de ensino superior, por meio de ações voltadas para a defesa da equidade socioeconômica, étnico-racial e de gênero. Seja por solicitação dos alunos da educação básica, por recomendação de suas professoras ou por meio das situações de violência contra mulheres e homossexuais percebidas no interior das escolas envolvidas, o estudo sobre questões de gênero esteve direta ou indiretamente presente em todos os seis projetos interdisciplinares já efetivados. A atenção a este assunto é justificada, principalmente, porque a agressão física, os xingamentos e outros tipos de ofensa têm sido alguns dos recursos utilizados por crianças e jovens que, por razões homofóbicas ou sexistas, atacam seus pares nos diferentes espaços da escola.

Diante da complexidade e da seriedade que o assunto merece, compor atividades de caráter pedagógico que auxiliem aos estudantes rever e alterar suas concepções, sem imposições ou prescrições, tem sido um desafio para o Grupo PET Conexões de Saberes/Interdisciplinar que, em 2017, percebeu mais uma vez a intensidade desses conflitos. Isso os instigou a estudar mais a fundo o assunto e, em consonância com os

${ }^{5}$ Este grupo surgiu em 2014 e está vinculado ao Programa de Educação Tutorial (PET), ligado ao Ministério da Educação e à Secretaria de Educação Superior (MEC/SESU). É coordenado pela profa. Mônica Vasconcellos e está abrigado na Faculdade de Educação. Em parceria com escolas públicas da educação básica, o grupo conta com 14 licenciandos dos cursos de História, Matemática, Geografia, Letras e Pedagogia que, em acordo com um plano de trabalho previamente preparado e aprovado por comitê específico e pelo próprio Ministério da Educação (MEC) realiza, coletivamente, um conjunto de ações, ora concomitantes, ora consecutivas, em parceria com escolas públicas da região. Integram este grupo: Bruna Assis da Silva, Thais Pio Marques, Pedro dos Santos Carvalho, Irene K. V. Labi Medeiros, Nara Irley dos Santos, Carlos Vieira R. Junior, Pedro Domingos B. Cachapuz, Douglas da Silva Araujo, Ana Paula Silva de Jesus, Juliana Silva Amorim, Davi Ferreira Nogueira, Vinicius Andrade e Thaís Pinheiro.

${ }^{6} \mathrm{O}$ colóquio foi uma iniciativa do Núcleo de Didática e Formação de Professores da Faculdade de Educação da UFF e do Formar - Grupo de Pesquisas em Formação de Professores e Práticas Pedagógicas.

RIAEE - Revista Ibero-Americana de Estudos em Educação, Araraquara, v. 13. n. esp. 2, p. 1503-1517, set., 2018. ISSN: $1982-5587$. 
temas eleitos pelos alunos do oitavo ano da escola envolvida - "Gastronomia e Grafite" e "Outras culturas" - elaboraram os projetos intitulados "Da cozinha à rua, vidas que têm voz" e "Aulas sem Lei”; ambos pautados pelos Temas Transversais (BRASIL, 1997). Conteúdos de Língua Portuguesa, Matemática, História e Geografia (RIO DE JANEIRO, 2012) foram abordados, e um conjunto de objetivos foram definidos, dentre os quais elencamos: identificar diferentes formas de preconceito, discriminação e intolerância, desconstruindo sua reprodução em meio social; desenvolver uma atitude de empatia e solidariedade com aqueles que sofrem discriminação; reconhecer o papel feminino nas diversas manifestações artísticas como forma contra-hegemônica e perceber a ocorrência de opressões e repressões dentro do mesmo espaço e em tempos históricos diferentes.

As atividades propostas contemplavam estratégias pedagógicas variadas. Para melhor esclarecer este ponto, apresentamos parte de um encadeamento do qual fazem parte duas delas. No projeto denominado "Da cozinha à rua, vidas que têm voz", os alunos do oitavo ano entrevistaram as cozinheiras da escola e, a partir das informações suscitadas, produziram um memorial que narra a história de vida, o cotidiano, a relação com o trabalho no espaço escolar, com a produção/preparo dos alimentos e o perfil socioeconômico dessas mulheres. Estes aspectos foram esmiuçados e problematizados coletivamente. Gráficos e tabelas foram construídos, temas como a marginalização dessas trabalhadoras e sua "invisibilidade" na convivência diária com outros membros da própria comunidade escolar, foram pautados. Todo esse material foi exposto nos murais da escola, mobilizando, inclusive, a atenção dos sujeitos alheios a este processo e o encantamento das entrevistadas frente à valorização de suas histórias.

Por sua vez, o projeto "Aulas sem Lei" teve como inspiração para uma de suas atividades o Dia Laranja criado pela ONU Mulheres. Em razão desta proposta, os jovens estudantes e suas professoras foram convidados a participar de uma exposição sensorial organizada em um espaço da Faculdade de Educação, subdividido em três ambientes. Pelos ambientes, cada estudante transitava vendado e acompanhado por um/uma colega que se responsabilizava por narrar suas percepções acerca das esculturas, fotos, textos e tirinhas presentes naquele contexto. Todo o material exposto evidenciava mulheres/meninas brasileiras ou estrangeiras, em situação de violência física, psicológica ou simbólica. Músicas em estilos variados com histórias sobre mulheres também foram disponibilizadas

7 O título deste projeto foi formulado pelos alunos da escola que, após o desenvolvimento da última atividade, expressaram o prazer de participar de um trabalho como aquele e indicaram que esta denominação representava a liberdade que sentiram. 
e acessadas por meio de fones de ouvido. Trechos considerados marcantes foram assinalados pelos participantes ou representados com desenhos.

Ao término da aula, uma reflexão coletiva a respeito da desigualdade nas relações de gênero foi provocada, e propostas concretas de alteração, enfrentamento e possibilidades de denúncia no combate à violência foram formuladas e compartilhadas pelos partícipes. Quando o grupo retornou à escola, as professoras foram enfáticas ao assinalar avanços na qualidade das relações estabelecidas em sala de aula, especialmente no que diz respeito ao tratamento dado pelos meninos em relação às meninas.

Outra iniciativa do ano de 2017, ao percebermos o avanço do pensamento conservador sobre gênero no Brasil, e como isto está afetando as práticas escolares, inclusive através da censura e punição a colegas de profissão, foi a realização de um colóquio aberto ao público interno e externo à universidade. Neste, discutimos gênero, sexualidade, ideologia de gênero, Movimento Escola Sem Partido (MESP) e Movimento Educação Democrática (MED). A atividade reuniu 240 pessoas e foi organizada em três momentos: 1) uma discussão teórica e conceitual sobre os estudos de gênero, desmistificando-se a ideia de uma escola que ideologiza essa temática; 2) a socialização de experiências do grupo PET, das ações desenvolvidas na escola, que abordavam gênero e sexualidade; 3) a problematização do impacto do avanço do discurso conservador nas práticas escolares. A proposta deste colóquio deflagra o fato de que as questões sobre gênero e sexualidade habitam o espaço educativo, explícita ou implicitamente, e reconhece a escola e a universidade como sendo um lugar de contradições e tensões.

Através destas iniciativas, tanto das ações do Grupo PET Conexões de Saberes/Interdisciplinar quanto do colóquio realizado, garantimos espaços de problematização e discussão, mesmo em tempos de retrocessos democráticos e de ameaça a uma escola laica. Ao contrário do que proclamam os defensores da Escola Sem Partido, estas experiências foram marcadas pelas possibilidades de diálogo e defesa de uma Educação Democrática. Reiteramos, deste modo, que a escola e a universidade são e devem ser respeitados como espaços plurais e territórios privilegiados para o diálogo entre os diferentes sujeitos que atuam e compõem o campo educacional.

\section{Considerações finais}

Ao buscar problematizar o que, no nosso entendimento, são equívocos em torno da

RIAEE - Revista Ibero-Americana de Estudos em Educação, Araraquara, v. 13. n. esp. 2, p. 1503-1517, set., 2018. ISSN: 1982-5587. 
temática de gênero e sexualidade, promulgados pelo pensamento político conservador e suas consequências para a escolarização, mostramos exemplos de iniciativas de como estamos enfrentando este contexto, na formação de professores. Acreditamos que um caminho disponível para a universidade e do qual ela não deveria abrir mão é a promoção de espaços que promovam o diálogo e que fortaleçam a produção e a circularidade de conhecimentos sobre gênero e educação, de forma plural e democrática.

Destaca-se, neste artigo, que em oposição ao acalorado debate nacional que coloca em xeque o papel da escola como promotora de discussões que envolvam as questões de gênero, elas já permeiam, de toda forma, o cotidiano de alunos e alunas da escola formal. A experiência do grupo Grupo PET Conexões de Saberes/Interdisciplinar demonstra que, no dia a dia das escolas, existe uma demanda, por parte dos estudantes, de discussões que abordem questões sobre gênero e sexualidade. De forma intencional e provocada por práticas pedagógicas planejadas ou não, essa temática está presente no cotidiano escolar, tendo sido recorrentes, por exemplo, nas atividades desenvolvidas na escola básica, relatos de situações de violência contra as meninas e homossexuais. Ao inviabilizar essa discussão, as tensões que já estão presentes no espaço escolar se ampliam, afetando mais fortemente grupos mais vulneráveis, que não se enquadram num modelo de gênero normatizado e hierarquizado.

Em tempos de incertezas em relação à promoção de políticas públicas que promovam o debate sobre gênero e sexualidade nas escolas, torna-se urgente a criação de territórios de diálogo e o fortalecimento da natureza plural das instituições educativas em defesa de uma agenda comprometida com a igualdade de direitos e oportunidades para mulheres e homens, independente de gênero, raça, etnia e classe social.

\section{REFERÊNCIAS}

BRASIL. Ministério da Educação e do Desporto/Secretaria de Educação Fundamental. Parâmetros Curriculares Nacionais. Brasília: MEC/SEF, 1997.

BRASIL. Ministério da Educação. Secretaria de Educação Básica. Secretaria de Educação Continuada, Alfabetização, Diversidade e Inclusão. Secretaria de Educação Profissional e Tecnológica. Conselho Nacional da Educação. Diretrizes Curriculares Nacionais Gerais da Educação Básica. Brasília, DF: MEC, SEB, DICEI, 2013. Disponível em: <http://portal.mec.gov.br/docman/julho-2013-pdf/13677-diretrizes-educacao-basica/file>. Acesso em: 08 jan. 2018.

BRASIL. Projeto de Lei 867/2015. Inclui, entre as Diretrizes e Bases da Educação 
Nacional, o Programa Escola sem Partido, Poder Legislativo, Brasília, DF, p. 2, 2015.

GARCIA, M.; MENDONÇA, V.; LEITE, K. Discriminação e violência homofóbica segundo os participantes da $6^{\text {a }}$ parada do orgulho LGBT de Sorocaba-SP: subsídios para (re) pensar as práticas educativas. Cadernos de Pesquisa, São Luís, v. 22, n. 3, set./dez., 2015.

LOURO, G. L. Gênero, sexualidade e educação: uma perspectiva pós-estruturalista. Petrópolis, RJ: Vozes, 1997.

MACEDO, E. As demandas conservadoras do movimento escola sem partido e a base nacional curricular comum. Educ. Soc., Campinas, v. 38, no. 138, p.9-26, jan.-mar., 2017.

ONU MULHERES, Organização das Nações Unidas. Declaração e plataforma de ação da IV Conferência Mundial sobre a Mulher, 1995. Disponível em:

<http://www.onumulheres.org.br/wp-content/uploads/2015/03/declaracao_pequim1.pdf>. Acesso em: 02 fev. 2018.

PENNA, F. de A. Programa "Escola sem partido": uma ameaça à educação emancipadora. In: GABRIEL, C. T; MONTEIRO, A. M.; MARTINS, M. L. B. (org.). Narrativas do Rio de Janeiro nas aulas de História. Rio de Janeiro: Mauad, 2016.

PENNA, F. de A. Sobre o ódio ao professor: entrevista com Fernando Penna. Movimentorevista de educação, Niterói, ano 2, n. 3, 2015.

REIS, T.; EGGERT, E. Ideologia de gênero: uma falácia construída sobre os planos de educação brasileiros. Educ. Soc., Campinas, v. 38, n. 138, p.9-26, jan./mar., 2017.

RIO DE JANEIRO. Secretaria de Estado de Educação. Dez. de 2012. Currículo Mínimo uma proposta em discussão: História; Área: Ciências Humanas e suas Tecnologias. Disponível em <http://www.conexaoprofessor.rj.gov.br>. Acesso em: 07 jul. 2017.

SALLES, D. A concepção pedagógica e o projeto educacional conservador e reacionário do Movimento Escola sem Partido: uma crítica a partir da função de subjetivação do processo de ensino-aprendizado. Revista Aleph, ano XIV, n. 28 p. 64-87, julho, 2017.

SEPULVEDA, J. A.; SEPULVEDA, D. O pensamento conservador e sua relação com práticas discriminatórias na educação: a importância da laicidade. Revista Teias, v. 17, n. 47, out./dez., 2016.

SOUSA SANTOS, B. de. A democracia brasileira na encruzilhada. Carta Maior, fev. 2018. Disponível em: <https://www.cartamaior.com.br/?/Editoria/Politica/A-democraciabrasileira-na-encruzilhada/4/39358>. Acesso em 10 fev. 2018.

VASCONCELLOS, M.; MOREIRA, T. Desvalorização da educação democrática em tempos de escola sem partido: a escola em disputa e o ENEM como pretexto. Revista ALEPH Brasil, n. 29, Ano XIV, p. 423-443, dez., 2017.

VASCONCELLOS, M.; SANTIAGO M. Cursos de licenciatura e práticas docentes na

RIAEE - Revista Ibero-Americana de Estudos em Educação, Araraquara, v. 13. n. esp. 2, p. 1503-1517, set., 2018. ISSN: $1982-5587$. 
educação básica: relações entre o referencial freireano e a formação inicial inspirada pela interdisciplinaridade. Revista ALEPH Brasil, n. 28, Ano XIV, p. 185-205, jul., 2017.

\section{Como referenciar este artigo}

ALMEIDA, Sandra Maciel de.; JAEHN Lisete.; VASCONCELLOS Mônica. Precisamos falar de gênero: por uma educação democrática. Revista Ibero-Americana de Estudos em Educação, Araraquara, v. 13. n. esp. 2, p. 1503-1517, set., 2018. ISSN: 1982-5587. DOI: 10.21723/riaee.v13.nesp2.set2018.11657

Submetido em: $15 / 03 / 2018$

Aprovado em: 19/06/2018 